\title{
A diplomacia do iuanet: breves comentários sobre a internacionalização financeira da China (parte I - aspectos teóricos)
}

\author{
Luíza Cardoso de Andrade* \\ André Moreira Cunha*
}

RESUMO - O presente artigo avalia o processo recente de internacionalização da China, enfatizando sua dimensão monetária. Avalia-se a hipótese do iuane renmimbi se tornar uma moeda internacional como decorrência da ascensão chinesa à condição de potência global.

Palavras-chave: China. Internacionalização monetária e financeira. Iuane renmimbi.

\section{INTRODUÇÃO}

A crise financeira global aprofundou a tendência prévia de deterioração da posição financeira, externa ${ }^{1}$ e fiscal, dos EUA, com reflexos sobre o dólar, que vem experimentando uma tendência de depreciação desde o início do século XXI. Ampliam-se os questionamentos sobre a capacidade da moeda estadunidense seguir exercendo o papel de principal referência para contratos comerciais e financeiros, bem como sobre a posição nuclear dos ativos emitidos em dólar, particularmente a dívida pública do país, na hierarquia global da riqueza (Eichengreen, 2009a, Roubini, 2009). Ao mesmo tempo, tal decadência coincide com a ascensão econômica da China, cuja internacionalização vem passando, de forma rápida, mas não inesperada ${ }^{2}$, por distintas etapas: da abertura comercial e atração de investimento direto estrangeiro nas duas primeiras décadas que se seguiram às reformas lideradas por Deng Xiaoping, para a extroversão comercial e financeira, atingindo, nos anos pós-crise, a posição de maior exportador global e agressivo investidor.

No dia 23 de março de 2009, durante um encontro de G20, o presidente do Banco do Povo da China, Zhou Xiaochuan lançou um artigo propondo modificações nos Direitos

\footnotetext{
† A moeda chinesa é denominada Renminbi (RMB ou CNY), termo que significa “a moeda do povo”. Iuane é sua unidade de medida.

* Bolsista PIBIC-CNPq. Endereço eletrônico: luiza.c.andrade@gmail.com.

** Doutor em economia pela Universidade Estadual de Campinas (UNICAMP). É professor do Departamento de Ciências Econômicas da Universidade Federal do Rio Grande do Sul (UFRGS) e pesquisador do CNPq. Endereço eletrônico: andre.cunha@ufrgs.br. Versão: dezembro de 2010.

1 Segundo o World Ffactbook da CIA, em 30 de junho de 2009 o valor da dívida externa estadunidense era de \$13,45 trilhões. Em https://www.cia.gov/library/publications/the-world-factbook/geos/us.html, acesso em 20 de novembro de 2010 .

2 Sobre a estratégia de internacionalização da China e a diplomacia do Iuane ver Cunha, Biancareli e Prates (2007) e Cunha e Acioly (2009).
} 
Especiais de Saque do FMI para criar uma nova moeda de reserva internacional que substituísse - ou ao menos concorresse com - o dólar. Atualmente, os Direitos Especiais de Saque têm base em uma cesta de moedas que inclui o dólar, a libra, o euro e o iene. Entre as propostas de modificações, consta incluir novas moedas na certa - possivelmente o iuane renmimbi. ${ }^{3}$

Enquanto as dúvidas e especulações sobre o futuro do dólar e do iuane renmimbi como moedas internacionais não são assuntos novos, é nova a atitude chinesa. Embora a proposta não tenha recebido apoio significativo, saindo do foco das discussões posteriores do G20, ela reflete tanto o aumento da preocupação internacional com o poder de compra do dólar depois da crise - que afeta a China mais do que outros países, já que ela possui a maior reserva de dólares do mundo ${ }^{4}$, - quanto o fato de que a China está sabendo se utilizar da conjuntura gerada pela crise para dar novos passos em direção à internacionalização de sua moeda.

De fato, há evidências que parecem apontar que o iuane renmimbi vai ganhar força no médio prazo. As outras moedas que compõem reservas internacionais - a libra, o iene, o franco suíço e o euro - enfrentam diferentes obstáculos ao uso mais extensivo. A China já tem grande peso na economia mundial e busca aumentar sua influência, tendência que deve apenas aumentar dadas as expectativas de crescimento da economia chinesa (Cunha e Acioly, 2009). Como ressaltam Chen e Peng (2007) isso significa que é provável que o iuane passe a ter um papel de destaque no comércio e nas finanças internacionais com a diminuição das restrições a sua convertibilidade, embora não se deva esperar que ele venha a desafiar a posição do dólar, ou mesmo do Euro, em um futuro próximo.

Para avaliar algumas destas evidências à luz dos movimentos mais recentes da estratégia de internacionalização da China, este artigo está estruturado em duas partes. Aqui é feita uma breve discussão teórica sobre os requisitos necessários para a internacionalização de uma moeda, bem como são apresentadas algumas evidências iniciais sobre o processo recente de crescimento e internacionalização da economia chinesa. Na segunda parte, a ser publicada no próximo número deste Boletim avalia-se se o iuane renmimbi preenche os requisitos analisados teoricamente para viabilizar seu uso como moeda internacional. Nossa hipótese é de que a China entrou em uma nova etapa de seu processo de internacionalização onde a extroversão financeira está ganhando maior proeminência. Todavia, segue sendo prematuro vislumbrar o iuane renmimbi como uma moeda plenamente conversível e internacional.

\footnotetext{
3 Bottelier, 2009.

4 De acordo com os dados do Deutsche Bank, a estimativa das reservas internacionais da China no final de 2009 é de 2,4 trilhões.
} 


\section{ASPECTOS TEÓRICOS DA INTERNACIONALIZAÇÃO DE UMA MOEDA}

Uma moeda internacional é geralmente definida com sendo aquela cujo uso se estende para fora do seu país de origem, sendo utilizada em transações internacionais, ou seja, envolvendo não-residentes. Suas funções são paralelas àquelas de uma moeda usada apenas nacionalmente: enquanto meio da troca, ela pode ser usada no comércio com outros países, no mercado cambial como moeda intermediária, reduzindo o número de transações bilaterais e diminuindo os custos de transação, e ainda como moeda de intervenção; enquanto unidade de conta, ela pode ser usada no mercado financeiro para denominar títulos e obrigações, no mercado de bens e serviços para denominar preços internacionais, e oficialmente para a realização de pegging; e enquanto reserva de valor, ela pode constituir fundos de investimentos e reservas estrangeiras

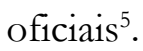

Embora essas diversas funções possam ser identificadas e analisadas separadamente e existam exemplos de moedas que cumprem pelo menos uma delas, mas não todas, é comum que exista uma moeda dominante que seja utilizada das três formas. Seus usos se reforçam mutuamente, podendo-se dizer que não são independentes, pois, como explica Krugman usando o exemplo da moeda estadunidense, "if the dollar is a good store of value, the costs of making markets against the dollar are lower, thus encouraging the vehicle role. Conversely, the mediumof-exchange role encourages both invoicing in dollars and holding dollars". ${ }^{6}$

O dólar tem sido a moeda dominante desde pelo menos a Segunda Guerra Mundial, papel que antes era cumprido pela libra esterlina. No entanto, desde a ruptura do Sistema Bretton Woods, há uma tendência à multipolarização, e outras moedas também desempenham papéis importantes, principalmente na formação de reservas internacionais, como é o caso do euro (antes deste, do marco), do iene, da libra e do franco suíço.

A literatura convencional considera que, ao contrário das moedas nacionais, cujo curso pode ser forçado através da lei, quando se trata de escolher uma moeda para transações internacionais, a decisão recai sobre os agentes. Os governos podem tomar iniciativas para incentivar ou inibir o uso internacional de sua moeda, regulando o grau de sua conversibilidade e a liberalização financeira externa. Todavia, tal perspectiva sugere que, em última instância, é o mercado que determina se certa moeda será usada ou não fora do seu país, sendo essa escolha "ratificada, mais do que guiada, por acordos internacionais"7.

5 A matriz de uso internacional da moeda, especificando suas funções privadas e oficiais é usada como base para a maioria dos trabalhos acadêmicos sobre o assunto. Segundo Thimann (2009), sua primeira elaboração está em Cohen (1971). Kenen (1983) é outra referência seminal.

6 Krugman, 1984, p. 269.

7 Krugman, 1984, p. 261. Tradução própria. 
Serão consideradas a seguir três variáveis principais que determinam a utilização de uma moeda internacionalmente. É preciso salientar que elas constituem, separadamente, condições necessárias, porém não suficientes, e que interagem entre si, reforçando-se mutuamente, assim como as funções anteriormente citadas. Isso significa que a internacionalização de uma moeda é um processo dinâmico que depende de diversos fatores.

As condições mais citadas na literatura como necessárias, conjuntamente, para que uma moeda seja usada em transações com não residentes são (i) o tamanho da economia doméstica e o volume de comércio que ela realiza com outros países, (ii) a estabilidade de seu valor e (iii) o desenvolvimento dos mercados financeiros nela denominados. Como veremos em uma análise mais detalhada de cada uma delas, elas são necessárias porque os agentes buscam reduzir os custos e os riscos ao escolher qual moeda vão utilizar.

Quando um país tem uma alta participação no produto, no comércio e nas finanças mundiais, ele provavelmente realiza muitas transações, o que significa que será mais provável que sua moeda seja aceita. Isso porque um agente está mais propenso a aceitá-la se sabe que não será difícil achar alguém que o faça no futuro. Atividades comerciais em grande escala criam um grande mercado de câmbio, diminuindo os custos de transação. Além disso, quando a economia doméstica de um país é grande e complexa, ela oferece um também grande mercado interno que utiliza sua moeda nacional, o que também ajuda a reduzir custos de transação.

É importante perceber, aqui, que há ganhos de escala no uso de uma moeda internacionalmente, já que os agentes a escolhem com base no fato de que muitos outros já estão se utilizando dela, criando externalidades em rede, o que quer dizer que quanto mais participantes de um mercado realizarem transações em uma moeda, mais conveniente será para os outros fazer o mesmo. Isso aumenta a importância de fatores históricos (path dependence), e não unicamente econômicos ${ }^{8}$ e também favorece as grandes economias, pois elas têm melhores condições de explorar e reforçar esses ganhos.

Já a crença na estabilidade política de um país e na estabilidade do valor de sua moeda é crucial porque taxas de inflação altas e instáveis e taxas de câmbio com alta volatilidade relativamente aos outros países indicam que a moeda pode perder valor repentinamente. Caso isso aconteça, comprometerá todas as funções de uma moeda internacional, pois aumentará os custos de recolher informações e realizar cálculos eficientes. Está claro que quando uma moeda que forma reservas internacionais perde seu valor os prejuízos para o país ou os investidores que as mantem é alto. O mesmo acontece quando ela é usada como meio de troca, pois há uma perda real para quem vier a recebê-la, e mesmo quando é simplesmente a unidade de conta, pois

8 Chinn e Frankel (2005) e Eichengreen (2003). 
os contratos têm de ser continuamente revisados, elevando os custos de transação. Para evitar que isso aconteça, é preciso que o país que emite a moeda mantenha políticas monetárias, fiscais e de câmbio que tenham credibilidade e estabilidade.

O desenvolvimento dos mercados financeiros também é decisivo: para que a moeda de um país ganhe relevância global, é necessário que ele conte com mercados financeiros extensos (com uma grande variedade de instrumentos financeiros), profundos (com mercados secundários bem desenvolvidos) e razoavelmente livres (com poucas restrições ao comércio e controles de capital). A profundidade dos mercados garante liquidez e aumenta a segurança; sua extensão atrai investidores por aumentar as possibilidades de maximizar ganhos e minimizar riscos e facilita o acesso a empréstimos e investimentos; e a abertura facilita transações internacionais e diminui custos de transação. Para tanto, é preciso dispor (i) de instrumentos sofisticados, (ii) de uma supervisão transparente e eficaz, (ii) de recursos legais que deem força aos contratos e (iv) de um banco central respeitado que possa agir como emprestador de última instância caso seja necessário.

Além disso, o país de origem de uma moeda internacional deve contar com instituições que possam realizar as operações necessárias em diversidade e volume, o que requer um setor bancário desenvolvido. Ao mesmo tempo, a expansão das atividades que se utilizam da moeda nacional pode ajudar o setor bancário doméstico a crescer, considerando a tendência dessas instituições a terem vantagens comparativas no que se refere à realização de operação com a moeda local.

Como foi mencionado anteriormente, as diferentes funções da moeda podem ser realizadas separadamente, e a presença, individual ou conjunta, de uma ou outras das condições acima citadas pode influenciar seu melhor desempenho na realização de uma ou outra função. Por exemplo, algumas moedas, como o iene e o franco suíço, podem se sobressair na composição de reservas, embora não sejam tão utilizadas como outras (e.g. o euro e o dólar) na denominação de transações comerciais.

Por fim, deve-se notar que qualquer análise histórica mostra que as mudanças no status internacional das moedas se dão muito lentamente. Há uma discordância entre os diversos autores que se dedicam ao tema quanto às razões disso: a maioria deles concorda que existe uma tendência à inércia, devida às externalidades em rede, ou seja, ainda que uma moeda deixe de cumprir satisfatoriamente uma das condições analisadas, os agentes continuam a utilizá-la por saber que os outros também o fazem. Alguns autores, no entanto,defendem que não há inércia, e o processo é lento porque são lentas e graduais as mudanças no que diz respeito a atingir ou não tais condições (Eichengreen, 2003 e 2005, Chinn e Frankel, 2005, Thimann, 2009). 
Para além destas precondições teóricas, a decisão da internacionalização de uma moeda envolve a consideração dos custos e benefícios associados a esse processo. A Alemanha e o Japão, por exemplo, por algum tempo não consideraram que os potenciais benefícios eram suficientes para abrir mão de ter maior controle sobre sua política macroeconômica, e tomaram medidas para impedir que sua moeda se internacionalizasse. Analogamente, a internacionalização de uma moeda não afeta todos os setores da economia da mesma forma.

As principais vantagens para um país do aumento da importância internacional de sua moeda são a diminuição do risco cambial, a possibilidade de seigniorage, o aumento das atividades das instituições bancárias domésticas e o ganho de prestígio e de poder político. Como desvantagens há a diminuição do poder de controlar as políticas macroeconômicas nacionais e o aumento na volatilidade cambial, com tendência à apreciação.

A fonte de grande parte dos benefícios trazidos para um país pela internacionalização de sua moeda é que ela torna possível evitar o risco cambial, diminuindo os custos em que uma alteração nas taxas de câmbio pode acarretar durante a realização de transações. Dessa forma, o risco seria transferido dos residentes para investidores, exportadores e importadores externos.

Possivelmente ainda mais valorizada por policy makers é a seigniorage, que consiste na possibilidade de realizar financiamento em sua própria moeda, reduzindo a necessidade de manter reservas internacionais, já que a ampla circulação global da moeda de um país permite que ele tome empréstimos no mercado internacional denominados nela própria. Além disso, se a moeda também é usada por outros bancos centrais como componente de reservas internacionais, os juros que o país emissor tem de pagar pelos títulos de sua dívida são mais baixos do que aqueles que seriam cobrados por outros credores. Obter essas duas vantagens pode ser do interesse do governo chinês, já que há a preocupação de reduzir os riscos a que o país está exposto atualmente ao acumular reservas em dólares.

Embora não haja nenhuma ligação necessária entre a moeda em que as operações são realizadas e a nacionalidade do banco que as realiza, como foi mencionado anteriormente, instituições bancárias desfrutam de vantagens comparativas ao realizar operações com a moeda de seu país, por serem sua principal fonte de liquidez. Assim, um aumento da demanda por ativos e das transações denominadas na moeda nacional causaria um aumento no volume de negócios para as instituições domésticas, levando o setor a se desenvolver e reforçando o papel internacional da moeda.

Soma-se a essas vantagens o aumento do prestígio e do poder político internacional, fator pouco destacado pelos economistas convencionais, já que é mais dificilmente men- 
surado e envolve a consideração de elementos considerados por muitos exógenos à economia (Helleiner, 2008). No entanto, sua contribuição para o entendimento da ênfase que a China vem dando à internacionalização do iuane é bastante significativo, principalmente quando observada no contexto da "ascensão pacífica" chinesa?.

Já entre as desvantagens, a que costuma pesar mais na decisão de não incentivar, ou mesmo de tentar impedir o uso internacional da moeda doméstica é a restrição das políticas macroeconômicas. Há cinco fatores que contribuem para diminuir o poder das autoridades nacionais de administrar essas medidas: (i) como as alterações nas políticas do país podem ter efeitos negativos para outros países, a internacionalização da moeda traz uma maior responsabilidade com a estabilidade global, diminuindo a liberdade de usá-la para alcançar objetivos internos; (ii) se os outros bancos centrais mantêm reservas da moeda nacional, o efeito das políticas macroeconômicas pode não ser tão amplo quanto seria caso isso não ocorresse; (iii) a maior volatilidade da taxa de câmbio sob um regime flexível dificulta a administração da política monetária; (iv) caso outros países adotem uma política do pegging com a moeda doméstica, fica mais difícil usar a taxa de câmbio para ajustar o balança de pagamentos; e (v) a depreciação da moeda pode afetar seu uso como reserva de valor.

Além disso, provavelmente haverá uma maior volatilidade na demanda por moeda e na taxa de câmbio. A maior flutuação na demanda se deve mais ao aumento da mobilidade de capitais do que da internacionalização da moeda em si; no entanto, as duas coisas estão relacionadas. ${ }^{10}$ Ademais, quando uma moeda é usada internacionalmente, torna-se mais difícil controlar seu estoque, o que também interfere nas políticas cambial e monetária.

Por fim, deve-se levar em conta que ocorrerá um aumento na demanda pela moeda doméstica, gerando uma tendência à apreciação que pode vir a diminuir a competitividade das exportações. No caso da China, que já sofre pressões para apreciar sua moeda, esse efeito poderia ser potencializado.

A posição cautelosa anteriormente adotada pelo governo chinês com relação à internacionalização de sua moeda é uma combinação desses fatores (Cunha, Biancarelli e Prates, 2007, Cunha e Acioly, 2009). Como será analisado na sequência, há indícios de que os formuladores da estratégia chinesa se preocupam com a instabilidade a que o país seria exposto com a diminuição dos controles sobre a conta capital ${ }^{11}$ e a liberalização dos mercados financeiros. Some-se a isso a expectativa de que as políticas macroeconômicas tenham sua efetividade diminuída.

9 Referências adicionais em Cunha e Acioly (2009).

10 Chinn e Frankel (2005).

11 Utilizaremos a expressão conta capital, consagrada na literatura, para fazer referência à conta capital e financeira do BP. 


\section{O CASO CHINÊS: INTERNACIONALIZAÇÃO FINANCEIRA E AS PERSPEC- TIVAS DO USO DO IUANE COMO UMA MOEDA INTERNACIONAL}

As reformas lançadas no final de 1978 representam um marco no processo recente de transformações da economia chinesa (Cunha e Acioly, 2009). O impulso à internacionalização ganhou um ímpeto redobrado após a entrada da China na OMC, quando o país assumiu alguns compromissos internacionais no que diz respeito a suas metas de abertura. Nesse período, o sistema bancário do país foi reformado, segmentos dos mercados de capitais foram criados e/ou alinhados aos parâmetros internacionais, o comércio foi liberalizado, o regime cambial foi alterado e procurou-se atrair capital e tecnologia do exterior e, posteriormente, aumentar a propriedade de ativos fora do país. Em outras palavras, vem se dando desde o final da década de 1970 uma transição lenta e gradual de uma economia planejada e fechada para uma economia de mercado globalizada.

O desempenho econômico do país desde então tem se destacado por suas altas taxas de crescimento do PIB, por sua crescente participação no comércio internacional e, mais recentemente, pela acumulação de reservas internacionais. Nos últimos meses, também o regime cambial chinês e seu crescente volume de investimentos diretos em outros países tem gerado discussões entre os economistas e formuladores de política (Miller, 2010) ${ }^{12}$.

Conforme destacado na seção anterior, quanto mais alta a participação de um país no produto, no comércio e nas finanças mundiais, mais fácil será a aceitação internacional de sua moeda. Os Gráficos 1 a 3 abaixo mostram o crescimento do PIB chinês e da sua participação no PIB mundial. A trajetória de rápida ascendência leva a China a uma posição de destaque entre os países emissores de moedas internacionais e até o segundo lugar entre as economias individuais. Considerado-se, também, as taxas e a tendência de crescimento desses países, veremos que a participação da China no PIB mundial deve continuar crescendo.

Juntamente com o crescimento da participação da China no comércio exterior, essa é a principal razão apontada para que a moeda do país passe a ser usada globalmente. De fato, os dados de comércio exterior apontam para resultados similares aos do PIB, como se pode ver no Gráfico 4, onde a China desponta como maior exportador de mercadorias do mundo no ano de 2009.

12 Ver, também: "China buys up the world", The Economist, Nov 11th 2010; "Being eaten by the dragon", The Economist, Nov 11th 2010. 
GRÁFICO 1 - PARTICIPAÇÃO NO PIB MUNDIAL (DÓLARES CORRENTES) DE ECONOMIAS SELECIONADAS, 1980-2009 (\%)

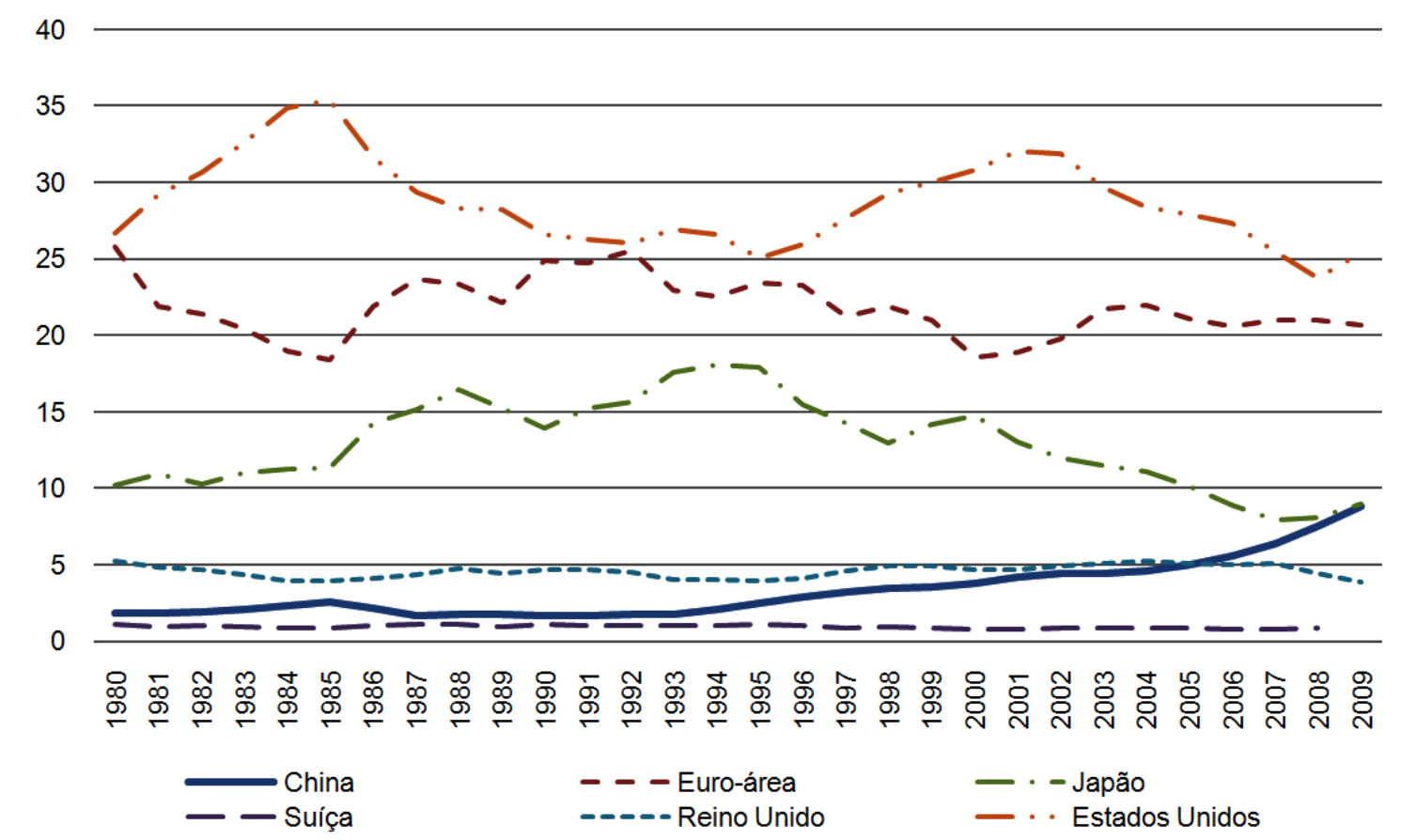

Fonte: Banco Mundial (World Development Indicators - online database).

GRÁFICO 2 - PARTICIPAÇÃO NO PIB MUNDIAL (PPP) DE ECONOMIAS SELECIONADAS, 1980-2009 $(\%)$

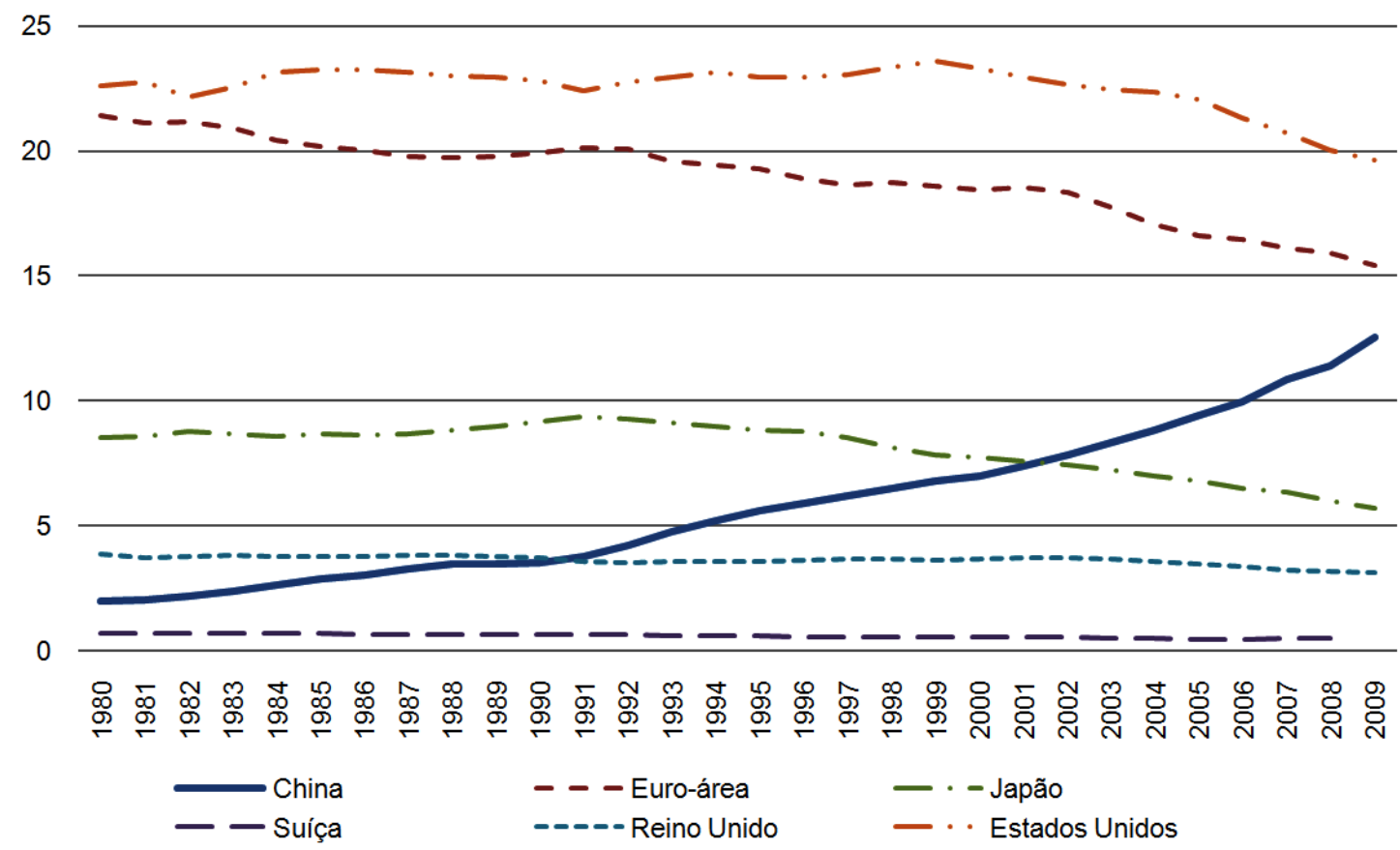

Fonte: Banco Mundial (World Development Indicators - online database). 
GRÁFICO 3 - TAXA DE CRESCIMENTO DO PIB EM ECONOMIAS SELECIONADAS (\% a. a.) 20
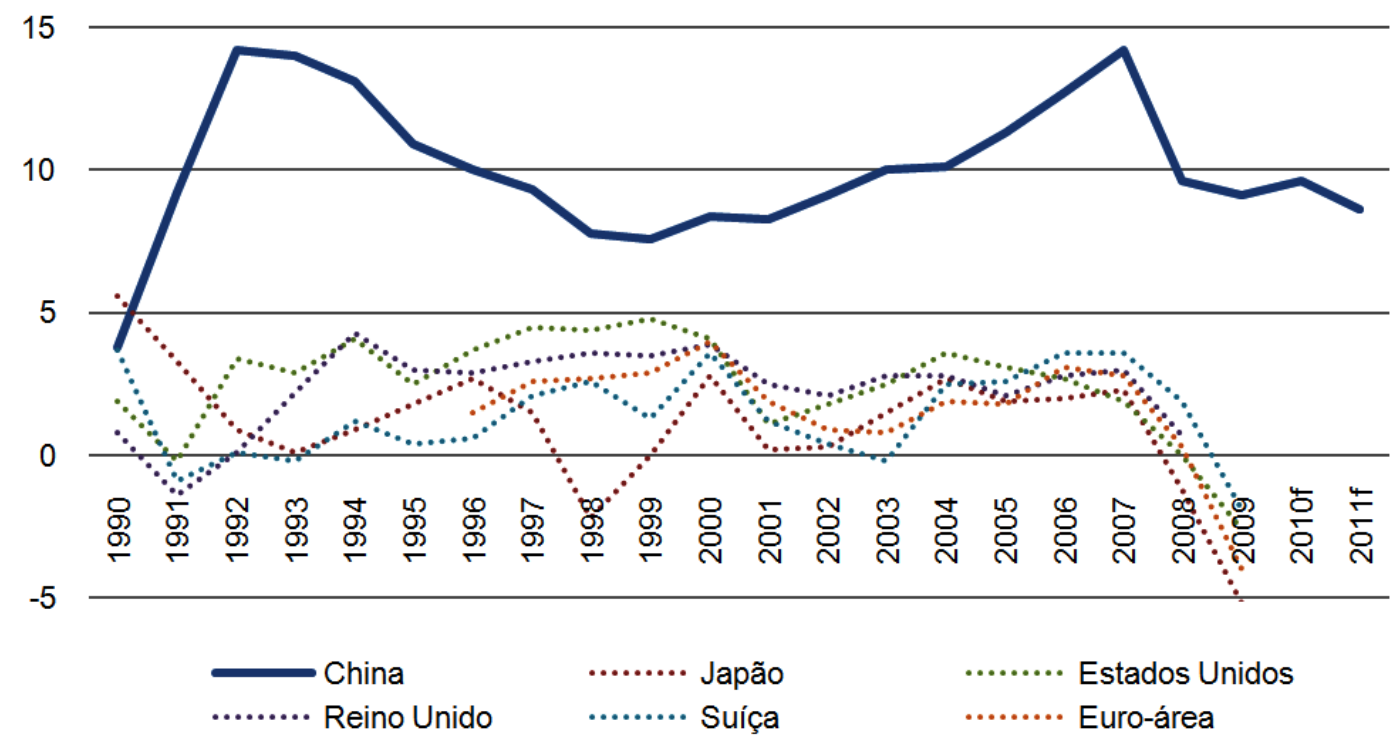

Fonte: Deutsche Bank Research.

GRÁFICO 4 - PARTICIPAÇÃO NAS EXPORTAÇÕES MUNDIAIS DE MERCADORIAS - ECONOMIAS SELECIONADAS, 1980-2009 (\%)

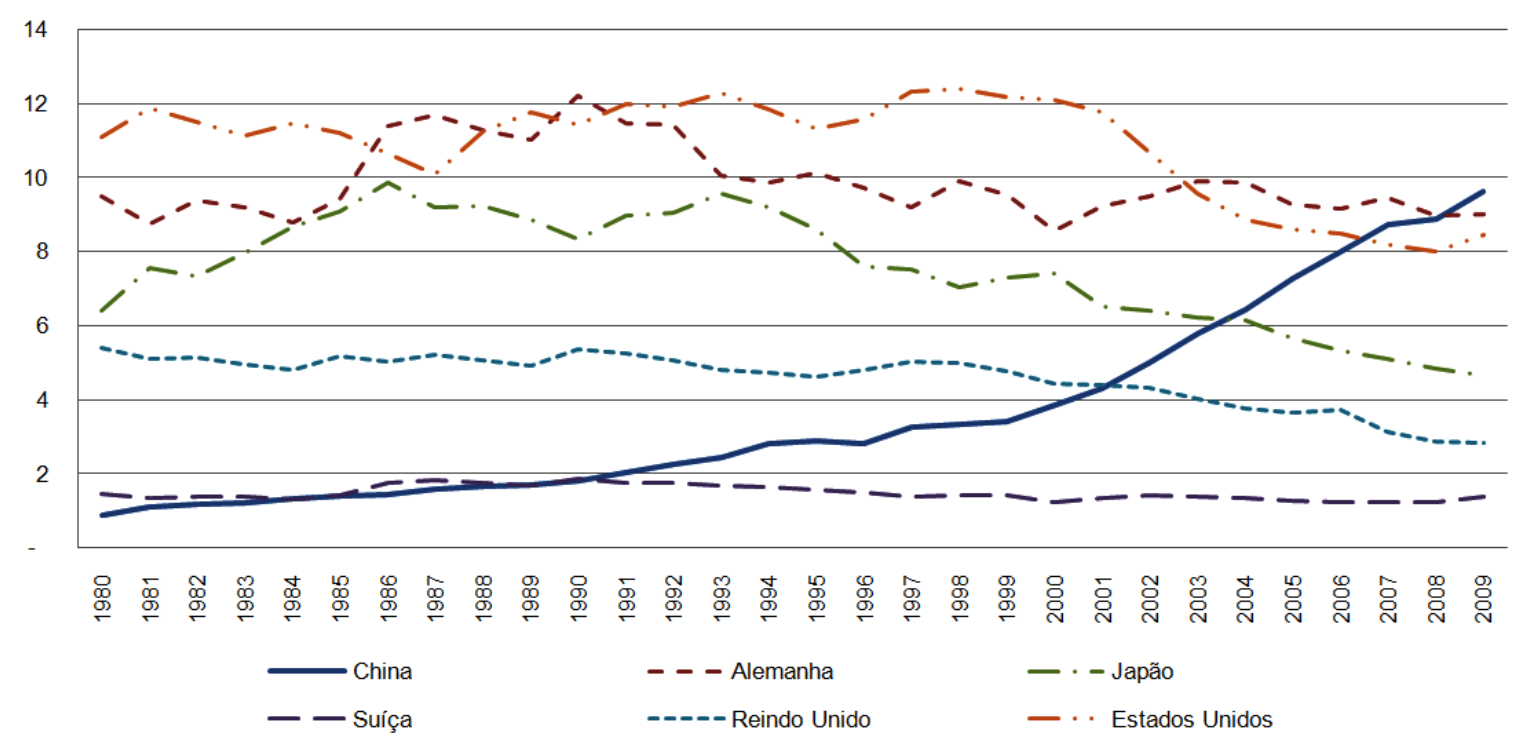

Fonte: Organização Mundial do Comércio (http://www.wto.org/english/res_e/statis_e/statis_e.htm).

Para avaliar a estabilidade monetária parte-se da percepção de que o comportamento da inflação chinesa é convergente com o verificado nas economias emissores de moedas de reserva (Gráfico 5) e que a evolução do seu regime cambial tem minimizado oscilações abruptas em um período que o mundo experimentou diversas crises financeiras (Gráfico 6). 
GRÁFICO 5 - INFLAÇÃO, PREÇOS AO CONSUMIDOR EM ECONOMIAS SELECIONADAS, 1997-2009 (\% a. a.)

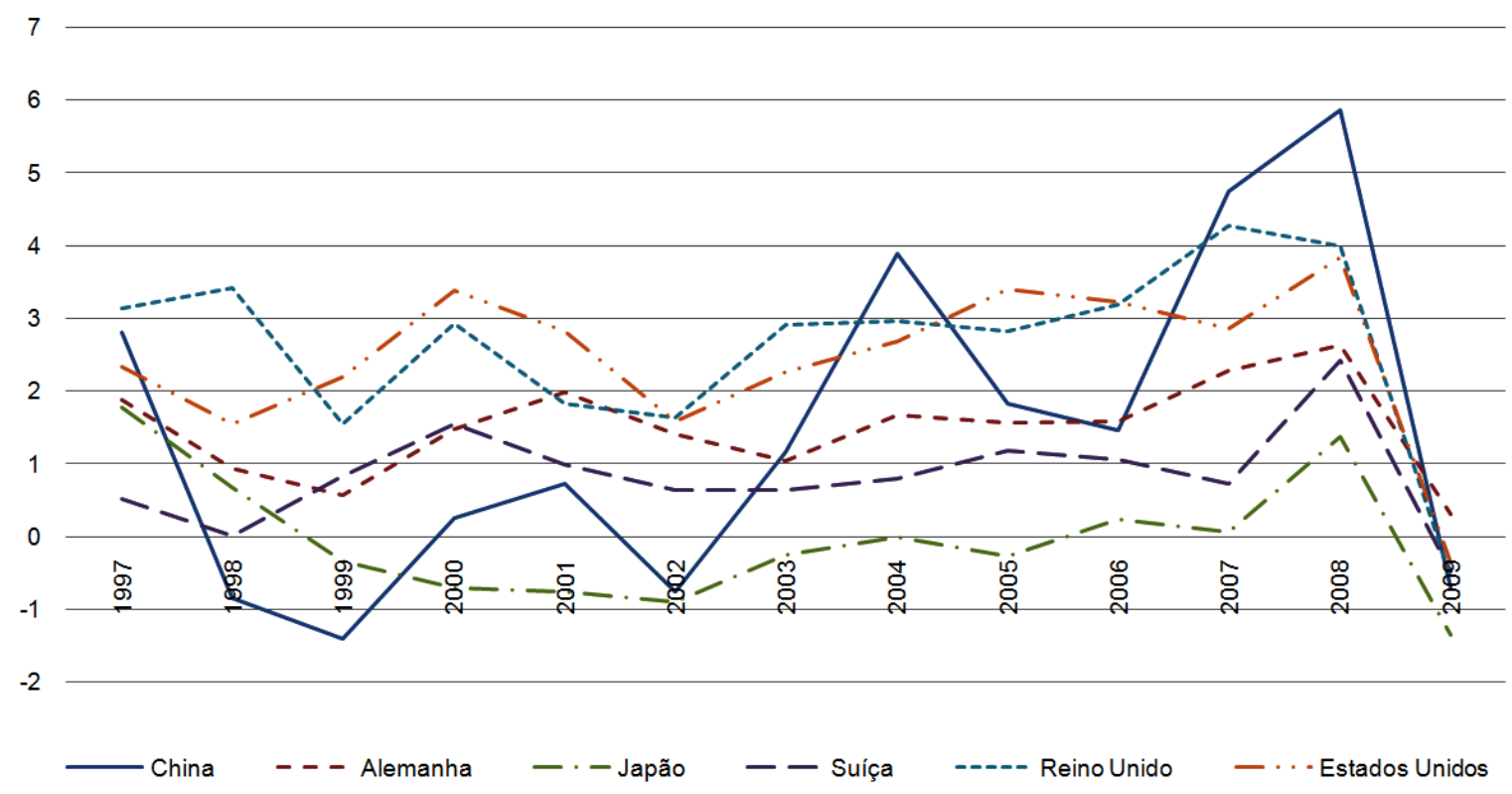

Fonte: Banco Mundial (World Development Indicators - online database).

GRÁFICO 6 - TAXA NOMINAL DE CÂMBIO (RMB/US\$)

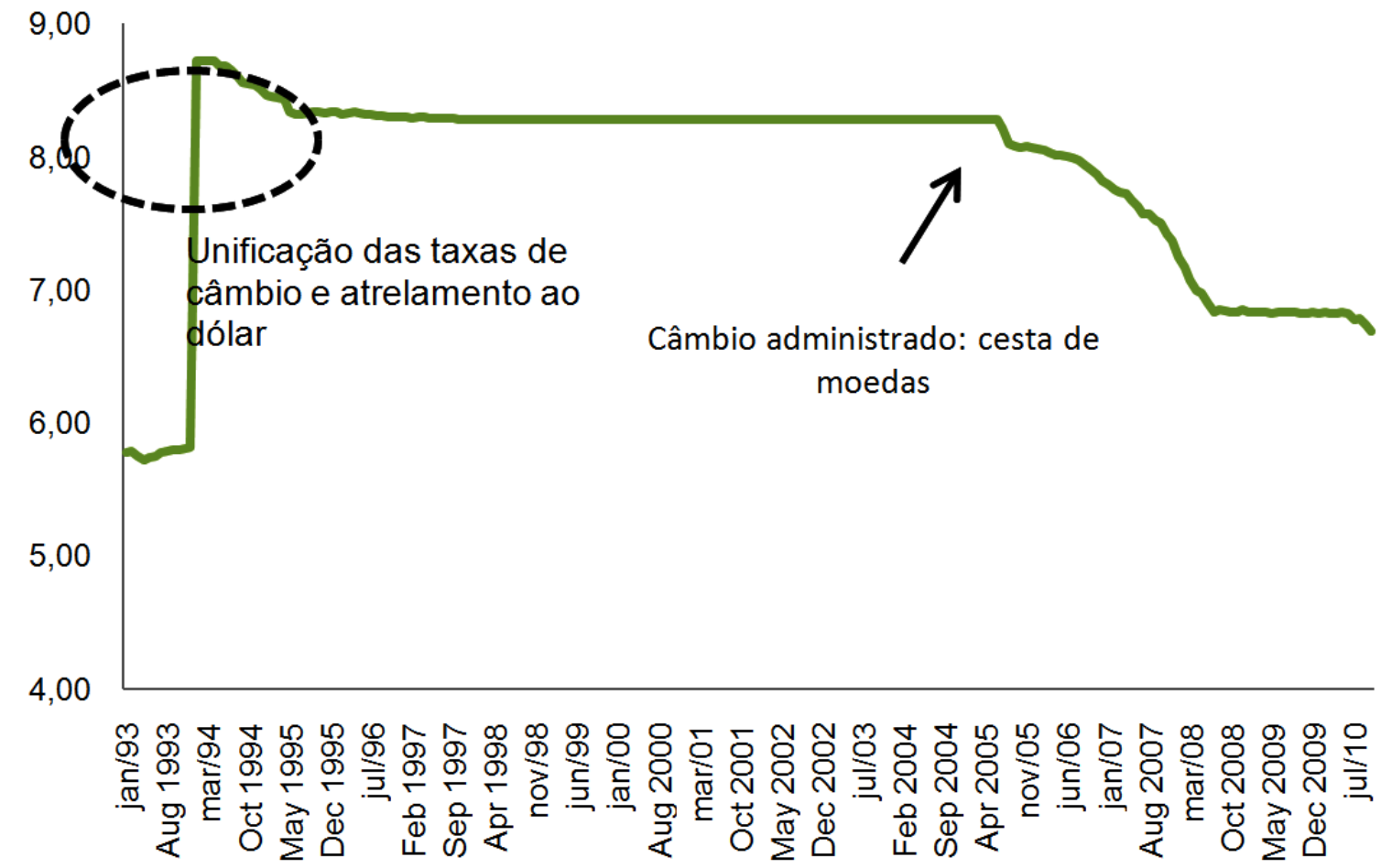

Fonte: Pacific Exchange Rate Service.

Por outro lado, o receio internacional com relação ao regime político chinês, representa um obstáculo a ser superado ${ }^{13}$. Não se trata apenas da centralização de poder em um único

13 Ver: Shirk (2007), Kang (2007), Miller (2010). 
partido, refletindo um padrão de governança que se afasta do verificado no mundo ocidental: todos os países cujas moedas tiveram projeção global até hoje apresentavam padrões bem mais elevados de renda per capita, urbanização, nível educacional, qualidade de vida, etc. Isso dava a esses países coesão social e estabilidade política que a China ainda não alcançou e que mesmo com as altas taxas de crescimento que vem apresentando ainda irá demorar a alcançar.

Novamente, no entanto, esse não parece ser o maior obstáculo à internacionalização do iuane no futuro próximo. Os principais entraves a um maior uso da moeda chinesa destacados pela literatura dizem respeito às dificuldades que os estrangeiros encontram para ter acesso à moeda chinesa: as restrições à conversibilidade da conta capital e financeira e os mercados financeiros pouco desenvolvidos limitam a quantidade de iuane que os agentes de outros países podem reter e impedem que sejam feitas aplicações denominadas nessa moeda. Este fato reflete uma estratégia consciente do governo chinês, que, no entanto, vem diminuindo gradualmente as restrições à conversibilidade e liberalizando os mercados financeiros (Cunha e Acioly, 2009). O ritmo impresso a esse processo determinará também o ritmo do aumento do uso internacional do iuane.

\section{CONCLUSÕES PARCIAIS}

Este trabalho tem por objetivo principal avaliar o processo de internacionalização financeira da economia chinesa. Nesta primeira parte foram tratados os aspectos teóricos da internacionalização de uma moeda, bem como algumas evidências iniciais para o caso chinês. A análise será complementada em uma segunda parte a ser publicada no próximo número deste Boletim.

\section{REFERÊNCIAS}

BOTTELIER, P. International monetary reform and the future of the remninbi. China Brief. Volume IX, Issue 11, 2009. Disponível em: <http://www.jamestown.org/single/?no_ cache $=1 \&$ tx_ttnews[tt_news] $=35039>$. Acesso em 11/2010.

CHEN, H., PENG, W. The potential of the renminbi as an international currency. China Economic Issues, November, 2007. Disponível em: < http://www.info.gov.hk/hkma/eng/research/cei/cei_f.htm>. Acesso em 07/2010.

CHINN, M., FRANKEL, J. Will the euro eventually surpass the dollar as leading international reserve currency? NBER Working Paper 11510, 2005.

COHEN, BENJAMIN J. The future of sterling as an international currency, London: Macmillan, 1971.

CUNHA, A. M. Integração monetária e financeira na Ásia-Pacífico: o que podemos esperar depois da crise. In: XV Encontro Nacional de Economia Política, 2010, São Luis. CD-ROM (Anais do XV Encontro Nacional de Economia Política). São Paulo: Sociedade de Economia 
Política, 2010.

CUNHA, A. M., BIANCARELLI, A. M., PRATES, D. M. A diplomacia do yuan Fraco. Revista de Economia Contemporânea, v. 11, p. 525-562, 2007.

CUNHA, A. M., SILVA, L. A. China: Ascensão à condição de potência global características e implicações. In: José Celso Cardoso Jr.; Luciana Acioly; Milko Matijascic. (Org.). Trajetórias Recentes de Desenvolvimento: estudos de experiências internacionais selecionadas. Brasília, 2009, v. 2, p. 343-396.

DOBSON, W., KASHYAP, A. The contradictions in China's gradualist banking reforms. Brookings Papers on Economic Activity, v. 2. September, 2006.

DOBSON, W., MASSON, P., Will the renminbi become a world currency? China Economic Review, 20, 124-135, 2009.

EICHENGREEN, B. A globalização do capital. São Paulo: Editora 34, 2003.

EICHENGREEN, B. Sterling's past, dollar's future: historical perspectives on reserve currency competition. NBER Working Paper n. 11336, Cambridge, MA, May, 2005.

EICHENGREEN, B. The dollar dilemma. Foreign Affairs, September/October, 2009a.

EICHENGREEN, B. The irresistible rise of the renminbi. Disponível em: <http://www. project-syndicate.org> em 23 de novembro de 2009b.

HELLEINER, E. Political determinants of international currencies: What future for the US dollar? Review of International Political Economy, 15:3 August, 354-378, 2008.

KANG, D. C. China rising: peace, power and order in East Asia. Columbia University Press, 2007.

KENEN, P. The role of the dollar as an international reserve currency, Occasional Papers n. 13, Group of Thirty, 1983.

KRUGMAN, P. The international role of the dollar: theory and prospect. In: Bilson, J. F. O., R. Marston, R. (eds) Exchange Rate Theory and Practice, Chicago: University of Chicago, 1984.

MA, G., HAIWEN, Z. China's evolving external wealth and rising creditor Position. BIS Working Papers No 286, 2009.

MA, G., MCCAULEY, R. N. Do China's capital controls still bind? Implications for monetary autonomy and capital liberalization. BIS Working Papers n. 233, 2007.

MILLER, K. Coping with China’s financial power. Foreign Affairs, July/August, 2010.

NAUGHTON, B. The Chinese economy: transitions and growth. Cambridge, MA: MIT Press, 2007.

PODPIERA, R. Progress in China's banking sector reform: has bank behavior changed? IMF Working Paper WP06/71, Washington, DC: IMF, 2006.

PRASAD, E., SHANG-JIN WEI. The Chinese approach to capital inflows: patterns and possible explanations, NBER Working Paper 11306, May, 2005.

ROUBINI, N. The almighty renminbi? The New York Times, May 13th, 2009. Disponível em: <http://www.nytimes.com/2009/05/14/opinion/14Roubini.html>.

SHIRK, S. L. China: fragile superpower. Oxford University Press, 2007.

TAVLAS, G.S. On the international use of currencies: the case of the deutsche mark. Prince- 
ton essays in international finance, n. 181, March, 1991.

THIMANN, C. Global role of currencies. ECB Working Papers, n. 1031, March, 2009. Disponível em: <http://www.ecb.europa.eu/pub/pdf/scpwps/ecbwp1031.pdf>. Acesso em 07/2010.

UBS. China bond market research. Londres, 4 de dezembro de 2006.

ZHOU, X. China's corporate bond market development: lessons learned. BIS Papers n. 26. Basle: Bank for International Settlements, 2005. 